\title{
Brownfield redevelopment, integrating sustainability and risk management
}

\author{
K. Pediaditi, W. Wehrmeyer \& J. Chenoweth \\ Center of Environmental Strategy, University of Surrey, U.K.
}

\begin{abstract}
Different definitions of risk too easily lead to differences in the type and level of risk accepted by varying stakeholders involved in the remediation process and redevelopment of contaminated sites as a whole. This can be rooted in the way risk information is interpreted and evaluated: technical risk definitions are largely evidential and based on engineering or technical contents, whereas social risk definitions are typically experiential and based on shared understanding and interpretation of information, including history and events. Brownfield redevelopments are characterised as high risk projects, due to potential onsite contamination, with some developers effectively redlining such sites. Yet, the Sustainable Urban Brownfield Regeneration Integrated Management (SUBRIM) Consortium identified that although contamination may be present on a site it may not always be the primary concern of the community affected by the redevelopment. It is argued here that risk is perceived by the public in a much more holistic, social way, which bears similar characteristics to the concept of sustainable development. The paper presents the results of a survey of perceived risks and impacts of a proposed development in Greater Manchester, UK, and draws conclusions for the need for risk communication and integration of the concepts of sustainability and risk, specifically with regards to brownfield regeneration projects.
\end{abstract}

Keywords: risk, sustainability, public, contamination.

\section{Introduction}

In 2004, brownfield redevelopment became a core objective to achieve sustainable communities [1] which is subsequently reflected in a number of strategic guidance and policy documents. In fact, the UK government has set a target that $60 \%$ of new homes should be built on previously developed land [2]. 
The rationale is that brownfield redevelopment offers the opportunity to create a more spatially integrated, mixed use urban environment but also to introduce resource efficient, high quality buildings [3]. Most importantly, Brownfield Redevelopment Projects (BRP) reduce the pressure to develop Greenfield sites.

However, POST [4] suggests that a significant proportion of developers effectively 'red-line' brownfield sites and prefer to develop on Greenfields as they perceive BRP to involve additional or at least increased risk. This comes from the potential for contamination and the risks this poses to the success and feasibility of the project [5]. In addition, BRPs have to deal with more, and more complex, issues and stakeholders, which itself causes uncertainty, in turn caused by a lack of environmental and redevelopment information on the type, location and significance of contamination [6]. Equally, environmental or health risks from contamination are subject to regulatory and planning procedures under Part IIA. Such procedures essentially require the assessment and management of risk and deal exclusively with technical, science-based risk. However risk is defined and perceived in many different ways and it is argued here that these different definitions of risk easily lead to differences in risk perception and acceptance by different stakeholders involved in the BRP and therefore the acceptability of the BRP as a whole (Section 2).

When deciding to start a BRP, a number of factors need to be considered, including human and ecological risks, technical feasibility, stakeholders, costs and benefits as well as more recently sustainability. However, [7] shows that these factors are interlinked and interdependent. This paper explores the interdependency of risk and sustainability (Section 3) and discussed their integrated consideration and management. It does so by reporting on a survey, questioning residents adjacent to a BRP on the risks they felt they were facing from the proposed BRP (Section 5 and 6). The extent to which contamination and its risks was seen as significant by the public is examined. Conclusions are drawn for future BRPs, including the need for a holistic integration of sustainability and risk management.

\section{Defining risk}

There are four broad ways in which people define risk, the first two are broadly evidential, the last two are largely experiential in their heuristic method.

\subsection{Technical definition}

Risk can be defined as the statistical probability for an event occurring, multiplied by the magnitude / scope of the event, often multiplied by some form of social response:

$$
\text { Risk }=[\text { Probability } * \text { Magnitude } * \text { Outcry }]
$$

Technical risk underlies most engineering-based approaches to remediation, including site sampling, and thus the complex decision-making process to remediate, and subsequently regenerate the site. This is particularly relevant 
under the UK approach to restoring sites according to "suitability for use" [5], where the level of remediation and the future land use are evaluated interdependently. It is labeled here as "evidential" because it uses empiricallyderived values as the basis for risk assessment and management. Because of its perceived objectivity and its technical background, it is also favoured by regulatory agencies, Local Authorities (LAs) and lawyers.

\subsection{Economic definition}

Here, risk is defined by means of an economic interpretation of the likely damage attributed to a statistical probability of an event, most notably in the calculation of damage under the Polluter Pays Principle [8]. Economic risk assessment of contaminated land typically includes issues of liability relating to:

- The clean-up costs themselves

- Liability for the remediation

- Loss of earning through project delay or reduced prices

- Future liability for residual contamination

- Legal recourse for specific aspects of the regeneration process

As with the technical definition, the economic definition of risk is essentially evidential because the assessment of risk depends on the data gathered on costs, and benefits, to the polluter.

\subsection{Psychological definition}

Psychologically, risk is subjectively based on personal backgrounds, culture circumstances, and institutional factors [9]. Risk is not expressed as a technically-derived number (a probability assessment), but is a qualitative and typically holistic, evaluation of something being "risky", "dangerous", "threatening" or "hazardous". Therefore it is essentially experiential.

Although there is a relationship between the technical assessment of risk and its psychological perception, they are not proportional in all cases. Equally, a psychological evaluation of low risk is not necessarily accepting it. This is because the empirical and experiential origins of risk are paradigmatically and ontologically distinct and are not immediately comparable, let alone tradable. Yet technically derived low estimates of risk are often seen as sufficient to define a risk as "residual" or "background", implying approval for accepting risk as "inevitable" or "normal" [10].

Previous and on-going research has identified some issues influencing psychologically-defined risk estimates which also affect risk acceptance of individuals or groups [10]. These are summarised in [7,pg 28] as:

- the degree to which the institutions assessing and managing the risk are trusted by the various stakeholders (i.e. involving issues of fairness openness and participation in decision making);

- $\quad$ the degree of dread felt by people in relation to the hazards present;

- $\quad$ the degree to which people feel familiar with the risks involved;

- the degree to which people feel in control of the risks to which they are exposed; 
- the degree to which the risks are known (including assumptions about contamination);

- $\quad$ the degree to which alternative options have been explored (and the use of the Precautionary Principle) [4,pg 3].

\subsection{Sociological and cultural definition}

Here, risk is defined through social and cultural factors, which provide a sensemaking framework of the situation [9]. This assumes the ability to develop a shared interpretation and understanding of hierarchical, egalitarian, individualistic, fatalistic and autonomous cultural patterns [12]. Beck [13] argues that we, as a society, through our individual activities and tacit as well as open acceptance of risk, define collectively the levels of risk we deem acceptable.

Currently, when dealing with potentially contaminated sites developers are required to focus on dealing with technical risks. It is also these technical risks and their regulatory or land use implications which deter some developers from BRPs.

\section{Sustainability and risk: two sides of the same coin?}

Grays and Wiedemann [14] argue that risk and sustainability could each benefit from more intensive recognition of their interdependence. The review of the most popular definition of sustainable development - "development which meets the needs of the present without compromising the ability of future generations to meets their own needs" [15: 43] - shows two important elements relating to risk: Firstly, sustainability is concerned with the future and decisions which affect it, yet the future is unknown so that such decisions involve uncertainty and thus risk with regard to unknown implications of current decisions. For instance, the Precautionary Principle states that "where there are threats of serious or irreversible damage, lack of full scientific certainty shall not be used as a reason for postponing cost-effective measures to prevent environmental degradation" [8: Principle 15]. However, in the sustainability literature risk is not directly expressed as an element of sustainable development.

Secondly, sustainable development and risk are ambiguous and mean different things to different people. Inherent to such understanding of both terms are personal values and perceptions - the psychological and cultural definitions of risk. These values shape what is to be sustained. Equally with risk, as the value attributed to a resource shapes what and how it is to be protected. Decision making with regard to sustainability and risk are based on human values and involves trade offs between risks and benefits.

Finally, a practical examination of BRPs and their relation to sustainability and risk show an important interrelation: Currently, a developer of such a site is unlikely to consider the sustainability of the project unless it is demonstrated that failure to do so involves (technically or economically defined) risks. A survey of a local community adjacent to a contaminated BRP in Greater Manchester 
evaluates below whether developers are right to worry about contamination risk and its public's perception or whether their concerns are in fact misplaced.

\section{Case study background and survey methodology}

1200 residents were surveyed living adjacent to a contaminated brownfield site of 18ha in the Greater Manchester area. The site borders an active landfill site, and consists of derelict paper mill, ancillary lodges (ponds) and some recreational facilities. A desk study of the site history and potential sources of contamination identified potential contaminants as metals and metalloids, acids, alkalis, inorganic chemicals, organic chemicals (e.g. PCB, PAH, fuel oils) and asbestos. Proposals have been made to develop some industrial units, a high school and 800 residential units, with the remediation survey currently ongoing.

The survey aimed to identify perceived impacts residents felt would occur as a result of the development and consisted of questions on different impact categories coded on a score from -5 to +5 as to whether they felt a significant positive or negative impact would occur, followed by a the option for a qualitative justification or explanation of their scoring. Open questions asked to write three main concerns regarding the proposal as well as aspirations for the site. Respondents were also asked to prioritise given social, economic and environmental objectives, considering the locality's needs. This offered an evaluation of respondents' key values and sustainability priorities. Finally, respondents were asked about the perceived importance of different types of risks from the BRP to study the role which technically defined and risk of contamination plays in gaining public acceptance of the overall proposals.

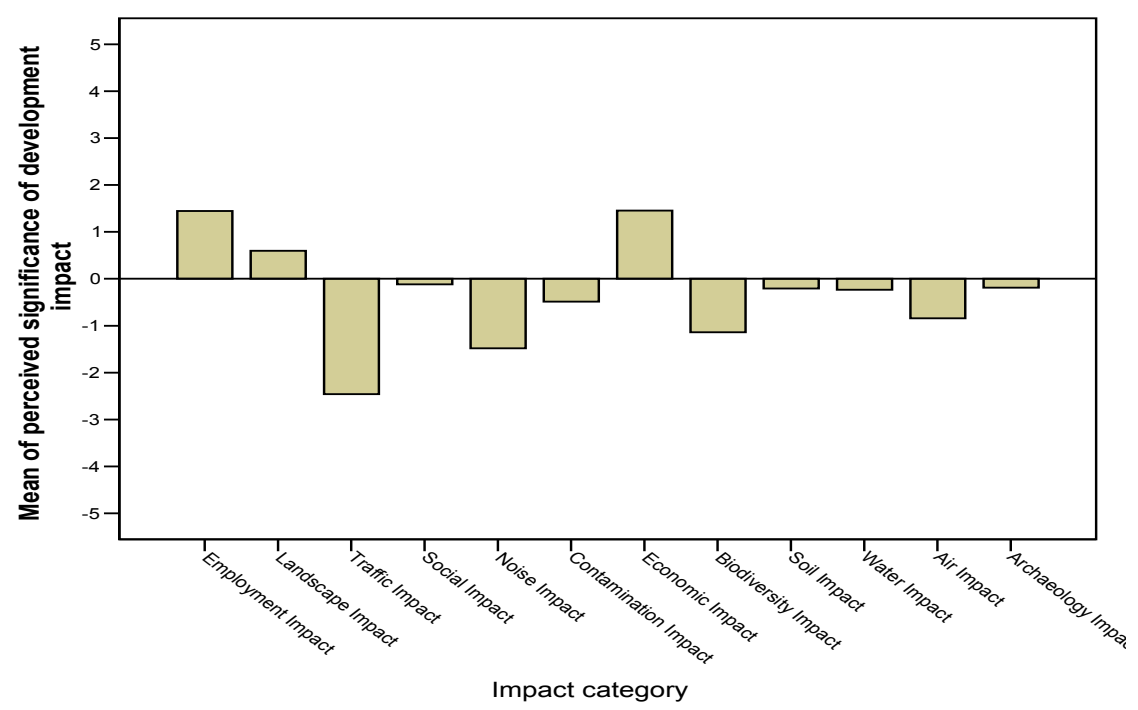

Figure 1: Perceptions of the BRP on different issues. 


\section{Results}

A $11.75 \%$ response rate was achieved, typical of this type of survey. Regarding the perceived significance of the proposal's impact on different issues or topics (fig 1), residents believed the proposals would have slight positive significant impact with regard to the economy, employment and the landscape. This was justified by stating that new residents would strengthen the town economy, and that employment would be generated during the construction phase. Residents identified traffic as the most significant negative impact and gave negative scores to noise and air quality which they attributed to the traffic. Biodiversity also was perceived to be affected negatively which many residents justified as occurring as a result of loss of the lodges and park/ recreational facilities.

\section{Table 1: $\quad$ Priorities of sustainability objectives}

\begin{tabular}{|l|c|c|c|}
\hline & $\mathrm{N}$ & Mean & Std. Deviation \\
\hline Provide a safe environment for people to work and live in & 139 & 3.25 & 2.607 \\
Minimise pollution and remediate existing contamination & 139 & 3.63 & 2.654 \\
Protect the landscape & 139 & 4.24 & 2.911 \\
Protect biodiversity and the natural environment & 139 & 4.25 & 3.213 \\
Provide adequate local service to serve the development & 139 & 4.83 & 2.745 \\
Promote the local economy & 139 & 5.34 & 3.191 \\
Integrate development within the locality & 139 & 5.53 & 3.119 \\
Provide employment opportunities & 139 & 5.71 & 3.948 \\
Protect heritage and historic buildings & 139 & 6.37 & 3.608 \\
Provide accessibility for all & 139 & 6.81 & 3.515 \\
Provide housing to meet needs & 139 & 6.83 & 3.444 \\
Minimise the use of resources & 139 & 7.04 & 3.878 \\
Provide transport infrastructure to meet business needs & 139 & 7.94 & 4.221 \\
Support local business diversity & 139 & 8.40 & 4.086 \\
Enable businesses to be efficient and competitive & 139 & 9.55 & 4.667 \\
\hline
\end{tabular}

Regarding the perceived priorities of sustainability objectives according to local needs (Table 1), although a social objective (provision of a safe environment), ranked first, many environmental objectives ranked highly such as the minimisation of pollution and the remediation of contaminated land, the protection of the landscape and biodiversity. Economic objectives in general were not a priority. This can be justified when looking at the context of the site, which mainly consists of social housing and many derelict buildings with limited open green areas and limited landscape amenities.

When questioned on the extent they faced different types of risks, environmental risks ranked the highest (Figure 2). However, all types of risks 
were of some concern mainly in the slightly (2) to moderately zone (3) with economic risks scoring the lowest followed by human heath and safety risks.

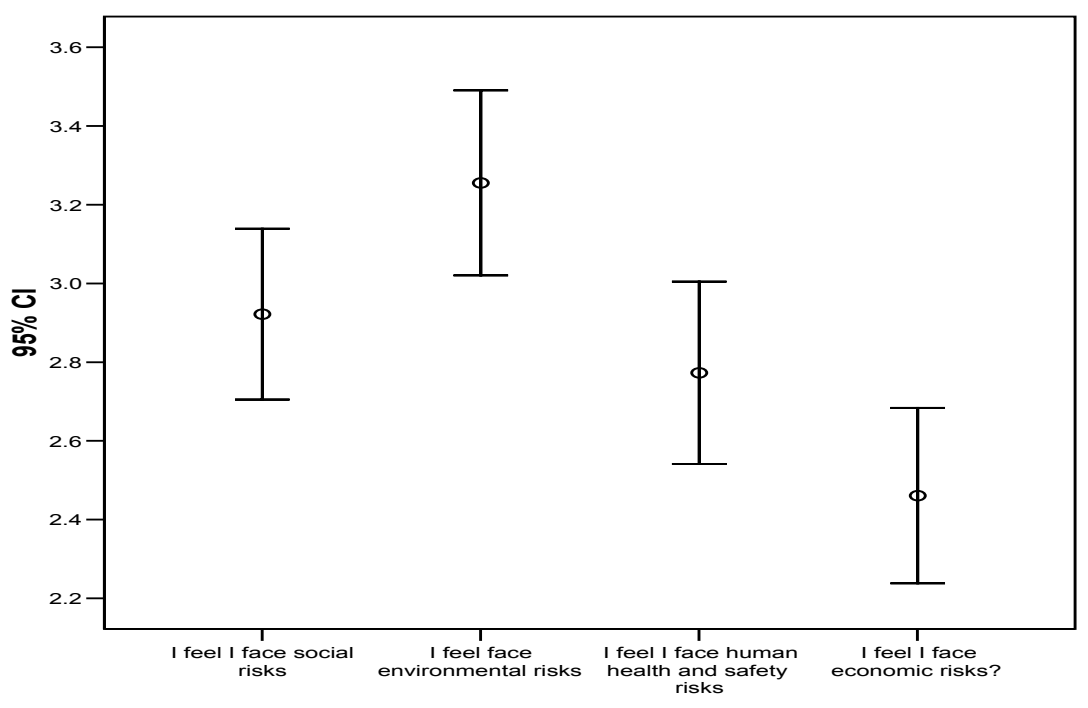

Figure 2: $\quad$ Perception of different types of risks faced.

\section{Discussion}

Although the remediation of contaminated land and reduction of pollution was ranked as the second most important sustainability objective for the site (Table 1) residents did not seem to perceive a significant negative impact from contamination (fig 1). Although overall a slightly negative impact score was achieved, the responses span between positive and negative, unlike traffic for example where all responses were negative. Respondents who saw the proposal as having a positive impact on pollution and contamination justified it with reference to the remediation works carried out at the time of survey. However, where respondents saw a negative impact they were not referring to the ground contamination but to traffic pollution being generated by HGV movements on the site during remediation, as well as concerns of littering once the proposed school is operative. Interestingly, respondents overall only felt slightly concerned by potential health and safety risks associated with the BRP (fig 2) with social and environmental risks ranking higher, although many respondents will be sending their children to the school on the site, which is known to be contaminated. Equally, when asked about their three greatest concerns, the site's contamination was never mentioned. The above results show how the public perceives and evaluates risk using the psychological and socio-cultural definition of risk which, as argued, is not directly correlated to the technical definition of 
risk. Likewise, it is useful to explore the factors which may have played a role in developing the above perceptions and relate it to risk perception literature.

Familiarity is considered to play an important role in influencing risk perception. As many of the residents surveyed potentially worked on the Paper Mill prior to its closure in 2002, respondents may be shaped by an experiential approach to risk perception and familiarity with the site may not have felt human health risks related to the contamination as being of particular concern and thus the "dread factor" was reduced [7]. However it is these human health and safety risks which mainly deter developers from developing of brownfield sites and it is these types of risks which are addressed through current planning and regulatory processes, thus failing to address the socio-cultural and psychological definitions of risk by the public which are more experiential.

Interestingly in this case study, environmental risks were considered to be of the greatest concern and had a significant difference in relation to human health risks and economic risks (Fig 2). This result is also supported through the perceived impact results (Fig 1) and the qualitative responses, where traffic was identified as most important as well as the loss of biodiversity (Fig 1). Here the experiential nature of risk perception is once again dominated as the area is known for its traffic and congestion problems therefore residents have the familiarity of the risk issue, which they associate with negative experiences. As traffic has been an ongoing phenomenon, a lack of confidence and trusting the Local Authority managing (or not) the issue has been fostered in the community. Furthermore, the loss of biodiversity which is also included in the environmental risk category and the perceived risk once again can be related to factors such as the lack of trust but also that of control [7] as the lodges had recently been drained when the survey was conducted.

Therefore, the public considers different types of risk using mainly psychological and socio-cultural definitions of risk. The levels of these experiential perceptions of risk were based on factors such as familiarity, trust perceived control as well as previous experience of the perceived risks, which is in line with much of the literature $[7,9]$. It is also demonstrated the different definitions of risk are not mutually exclusive, but do co-exist (Fig 2). Roth [17] also argues that lay people assess risk in a more holistic way which takes into account social environmental and economic impacts of risk related decisions, rather than narrowly focusing on the technical aspect of risks relating to health impacts. This is more in line with the concept of sustainable development, as it allows a balancing or a trade-off between different aspects of risk and it sees risk not in a reductionist, compartmentalised manner. This was illustrated through the results where residents were able to weigh the environmental risks up against the perceived economic benefits of the BRP, such as strengthening of the local economy and increased employment and thus expressed only slight concern with regard to economic risks. However, risk decision-making, as currently undertaken in the UK, and beyond, is one-dimensional considering predominantly the technical aspect of risk, as defined by experts, thus failing to take a multidimensional holistic assessment, which also integrates lay people's perceptions of risk which do not necessarily focus on the issue of contamination either. 
However, to suggest that, therefore, technical risk assessments (including site surveys and their resulting remediation strategies etc) can be replaced by public consultation would be irresponsible. The need for expert information on technically defined risk regarding contamination is not disputed, but the exclusive consideration of technically defined risks in BRP decision making is, as important issues affecting the overall sustainability and potential public acceptability of the BRP may omitted through this approach.

When considering remediating a site, technical risks will be assessed and, based on the results, a risk management plan potentially incorporating a remediation strategy will be implemented. However, due to the nature of the technical risk assessment the social, environmental and economic direct and indirect risks will not have been considered when designing the risk management strategy. This omission can have serious repercussions, as even technically perfect remediation strategies have to be subsumed under their socio-economic, regulatory and public policy context. In this case study it was demonstrated that respondents where not so much concerned by the actual contamination on the site but rather with the traffic being generated for its remediation. Thus it is demonstrated that the narrowly focus approach to risk consideration purely on technically defined risk with contamination levels has resulted in jeopardising the sustainability as well as the public acceptability of the project. It is thus proposed by [16] that with regard to risk management decision-making, sustainability should be part of the factors in the equation, rather than basing decisions purely on technical elements of risk. This would then also provide the intellectual basis for integrating risk-based information under the planning mantra of sustainable development.

\section{Conclusion}

From this case study it can be concluded that a BRP in fact is no different to a Greenfield development especially with regard to public risk perception and acceptability as in both cases a large range of issues and potential risks need to be considered. Here, the public appears more concerned with environmental risks relating to traffic and biodiversity which are equally applicable to Greenfield projects, if not more. Therefore, developers should not necessarily be scared or put off by risks with regard to BRP because with regard to public perception they do not have to be different to a Greenfield project. If anything, developers should obtain the confidence to involve local people as they can weigh the risks against the benefits such as increased employment, improved landscape etc, against the potential human health risks, a task not possible through the technical definition of risk and related processes. In addition, the study shows that the public can and do weigh different dimensions of risk and different sustainable development dimensions in a complex trade-off, which it is sometimes suggested the public cannot or would not do. Furthermore, it was demonstrated that through the use of the concept of sustainable development, many different aspects and risks can be addressed in a way which the public can relate to. In conclusion, an inclusive approach involving both experts and the public in risk assessment and which 
ensures the inclusion and consideration of all definitions of risk through the utilisation of the concept of sustainable development is proposed.

\section{References}

[1] ODPM, Consultation paper on Planning Policy Statement1: Creating Sustainable communities, London, 2004.

[2] DETR, A better quality of life: A strategy for sustainable development in the UK, Cm 4345, The Stationary Office, London, 1999.

[3] DETR, Planning for sustainable development: Towards Better Practice, DETR, HMSO, London, 1998.

[4] POST, A brown and pleasant land-Household growth and brownfield sites, Parliamentary Office of Science and Technology, London, 1998.

[5] Syms, P., Contaminated Land, The practice and economics of redevelopment, Blackwell Science, Oxford, 1997.

[6] Wylie, J., \& Sheehy, N., Contaminated Land \& Risk Communication: Developing communication guidelines using a Mental Models approach, Land Contamination \& Reclamation, 7(4), pp 285-289, 1999.

[7] Pediaditi K., Wehrmeyer W. \& Chenoweth, J., Risk, its role in Brownfield redevelopment project decision making and conceptual commonalities to sustainability, CES Working Paper, 02/2005, ISSN 1464-8083, 2005.

[8] UNCED, 1992, Rio Declaration on Environment and Development, www.unep.org/Documents/Default.asp?DocumentID=78\&ArticleID=116 3

[9] Renn, O, Three Decades of Risk Research: Accomplishments and new Challenges, Journal of Risk Research, 1, pp. 49-71, 1998.

[10] Roth, E., Morgan, G., Fischhoff, B., Lave, L, Bostom, A. What do we know about making Risk Comparisons? Risk Analysis, 10(3), pp.375-387, 1990

[11] Slovic, P, Informing and educating the public about risk, Risk Analysis, 6, pp. 403-415, 1986.

[12] Thompson, M., Ellis, R., Wildavsky, A., Cultural Theory. Westview Press, Boulder, Colorado, 1990.

[13] Beck, U., Risk Society, Sage, London, 1992

[14] Grays R.C.R, \& Wiedemann, P.M., Risk Management and sustainable development: mutual lessons from the approaches to the use of indicators, Journal of risk research, Vol 2, No 3, pp201-218, 1999.

[15] WCED, Our Common Future. Oxford, Oxford University Press, 1987.

[16] Vegter, J.J., Sustainable contaminated land management: a risk-based land management approach, Land contamination and reclamation, 9(1), pp 95-100, 2001. 